\title{
Persistent superior oblique paresis as a manifestation of familial periodic cerebellar ataxia
}

\author{
P G Bain, G B R Larkin, D M Calver, M D O'Brien
}

Department of

Neurology, UMDS,

Guy's Hospital, London

SE1 9RT

P G Bain

M D O'Brien

Department of

Ophthalmology,

University Hospital of

Wales, Heath Park,

Cardiff CF4 4XW

G B R Larkin

Department of

Ophthalmology, UMDS,

Guy's Hospital, London

SE1 9RT

D M Calver

Correspondence to:

Dr P G Bain, Human

Movement and Balance Unit,

Institute of Neurology,

23 Queen Square, London

WCIN 3BG.

Accepted for publication

21 March 1991

\begin{abstract}
A brother and sister complained of persistent diplopia due to superior oblique palsies. The cause of their symptoms became apparent when they were diagnosed as having familial periodic cerebellar ataxia (FPCA), a rare autosomal dominant condition. Oral acetazolamide (250 mg twice daily) not only prevented all the periodic symptoms but also relieved their diplopia, which had been present between attacks.
\end{abstract}

\section{Case reports}

PATIENT A

Now aged 22 years, patient $A$, male, began at the age of 10 to have 'episodes of giddiness' about once a week, usually while taking exercise. The episodes would last about 10 minutes and, because he became unsteady, forced him to sit down. On the basis of minor electroencephalographic (EEG) abnormalities he was believed to have 'vertiginous epilepsy and was treated with anticonvulsants, but these were unhelpful and were withdrawn. At 16 he developed diplopia and was referred to an ophthalmologist. Examination revealed visual acuities of $6 / 6$ in the right eye and $6 / 5$ in the left. No field defects were present, and there was no significant astigmatic error. His head was tilted and turned to the left, and a right superior oblique palsy was apparent on testing his eye movements. This was confirmed on a Hess chart (Fig 1). There were no abnormal physical signs and in particular no cerebellar deficit.

\section{PATIENT B}

Now aged 19 years, patient B, female, had been healthy as a child except for a slight delay in speech development. At the age of 10 she began to get 'attacks' that occurred up to five times a week and might last several hours, consisting of intermittent diplopia, true vertigo, and unsteadiness of gait. The attacks were precipitated by exertion, emotional stress, and menstruation and were always relieved by sleep. On the basis of

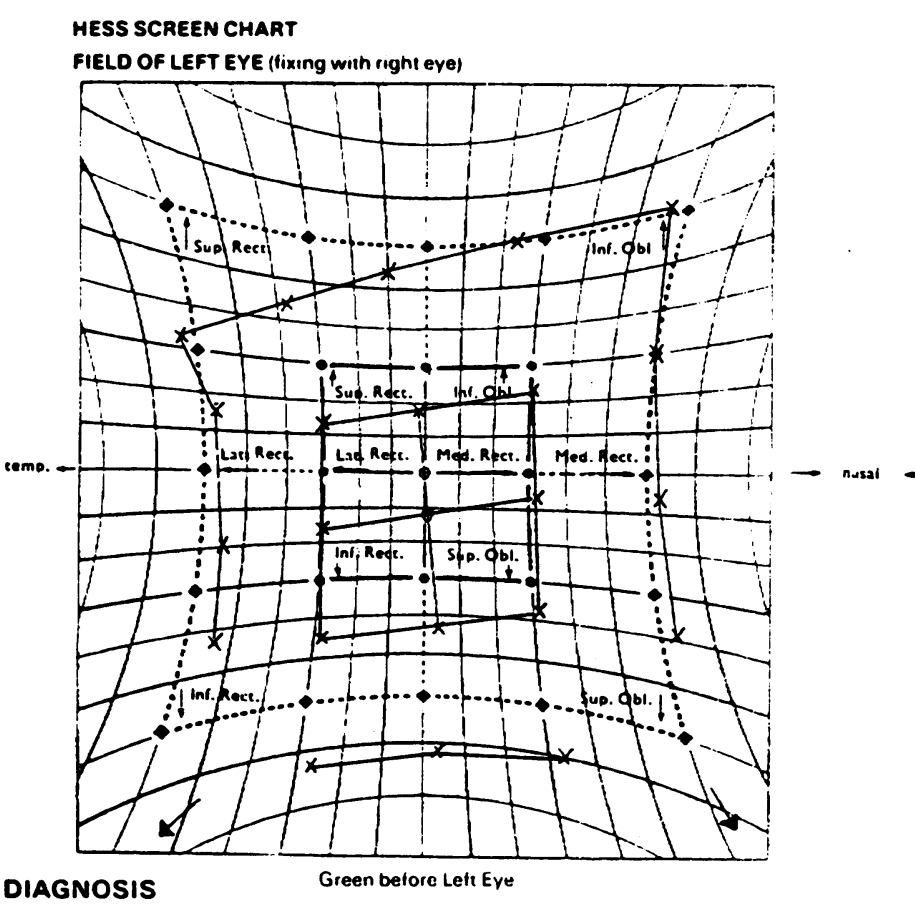

Name PATIENT. A .............. No

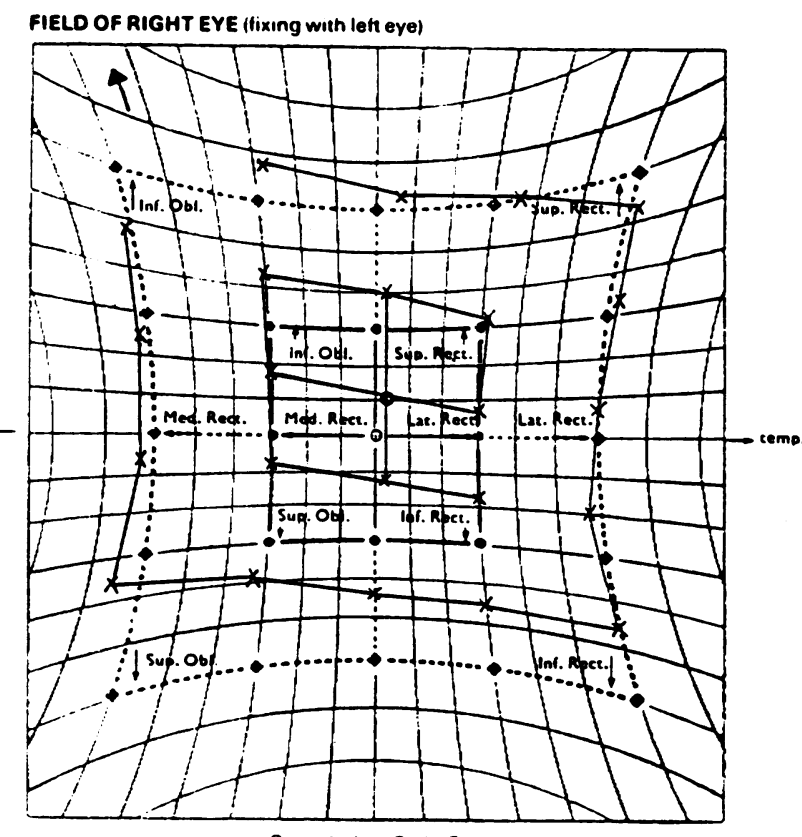

Figure 1 Hess chart demonstrating right superior oblique palsy in patient A. Ipsilateral (right) inferior oblique overaction and superior rectus underaction with contralateral (left) superior rectus underaction and inferior rectus overaction are also present, which suggests that the palsies are long standing. 


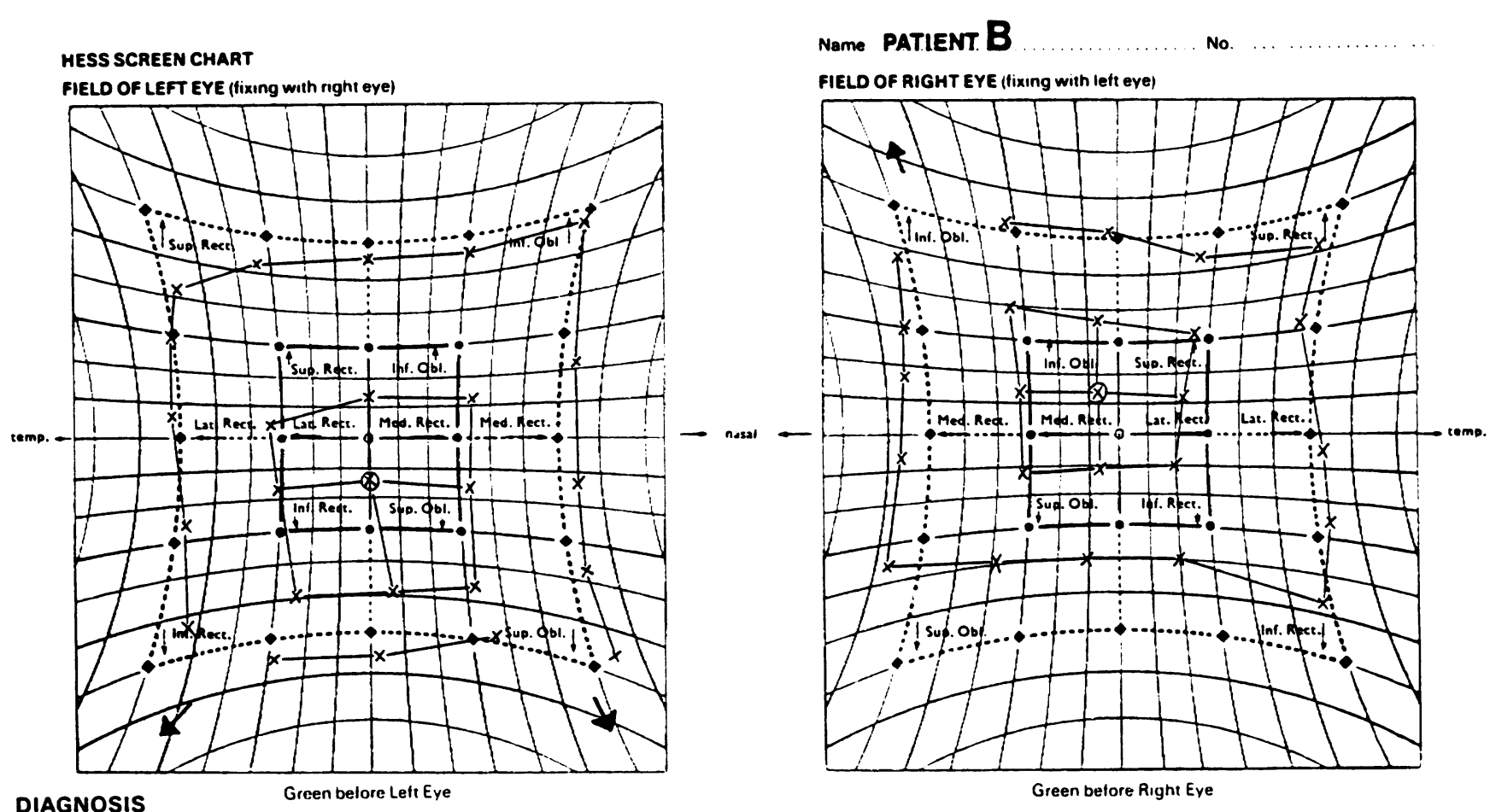

Figure 2 Hess chart demonstrating right superior oblique palsy in patient B. Details as for Figure 1 .

minor EEG irregularities, she was prescribed anticonvulsants, but these merely exacerbated her diplopia and increased the severity of the attacks and were eventually withdrawn. At the age of 13 she was referred for an ophthalmic opinion because of persistent diplopia. On examination her corrected visual acuities were $6 / 9$ bilaterally. She had normal visual fields and no significant astigmatic errors. There was a right superior oblique palsy which was recorded on a Hess chart (Fig 2). Her head was tilted and rotated to the left, but no other abnormalities were evident on general physical examination, and there was no cerebellar deficit.

The father of both patients had experienced similar 'giddy spells' since childhood. These episodes recurred weekly, lasted about 20 minutes, and consisted of slurred speech and incoordination of the lower limbs. He was unable to stand during an attack. Examination, between episodes showed ocular dysmetria, a scanning dysarthria, and transient first degree nystagmus on looking to the right. He had never complained of diplopia, and there was no evidence of an extraocular muscle palsy. No other members of the family appeared to be affected.

Table Types of nystagmus found, between attacks, in familial periodic cerebellar ataxia

\footnotetext{
(A) In primary position of gaze

(i) In primary positio

(i) Downbeat

(ii) Oblique

(B) Gaze evoked

(i) Intermittent $1^{\circ}$ horizontal

(ii) Persistent $1^{\circ}$ horizontal

(iii) Asymmetric horizontal (with increased amplitude of the jerks in the abducting eye)

(iv) Downbeat

(v) Upbeat

(vi) Combinations of horizontal and vertical
}

\section{INVESTIGATIONS}

Both patients underwent identical investigations, which included a cerebral CT scan, pure tone audiometry, optokinetic nystagmus, blood ammonia and amino acid assays, a full blood count, erythrocyte sedimentation rate, liver function tests, urea and electrolytes, blood sugar, vitamin $B_{12}$ and red cell folate levels, mid stream urine tests, and urinary amino acid assays; the results were all normal. Repeat EEGs were normal in both patients.

The family's intermittent symptoms suggested a diagnosis of familial periodic cerebellar ataxia. Treatment with oral acetazolamide ( 250 mg twice daily) abolished all their attacks, and Hess chart examinations confirmed that the superior oblique palsies had resolved. The effectiveness of acetazolamide has been maintained, without a single relapse, for over a year. Their diplopia has not recurred.

\section{Discussion}

Familial periodic cerebellar ataxia was first described by Parker in 1946.' Since then several families have been described ${ }^{2-13}$ in which disabling attacks of dysarthria, limb ataxia, and dysequilibrium occur. In the majority of these families the attacks have lasted from 10 minutes to 6 hours, were inherited as an autosomal dominant characteristic, and were preventable by oral acetazolamide. Between ataxic episodes the patients were usually asymptomatic and on examination were completely normal or had mild cerebellar signs, including the following ocular motility disorders: bidirectional square wave jerks on attempted fixation, broken pursuit movements, dysmetric saccades, and the types of nystagmus documented in the Table. In one very atypical case, a 3-year-old with craniofacial 
dysmorphism $^{12}$ (kindred II, patient IV-35), ptosis was observed, and in one other case ${ }^{5}$ (case 3) decreased upgaze was reported.

Our observation of persistent right superior oblique palsies in siblings with FPCA is unique and illustrates the heterogeneity of the eye signs in this condition. The responsiveness of their diplopia to acetazolamide, which also abolished their attacks, suggests that the palsies were not coincidental but the direct result of the underlying defect in FPCA. Evidently this disease can affect systems outside the cerebellum and its connections, in our cases involving the IVth nerve or superior oblique musculature. This suggestion is supported by Trillet $e t a l,{ }^{11}$ who observed abnormalities in the visual (longer lag period) and somataesthetic (slowed conduction rate in the medial lemniscus) evoked potentials of their patients.

FPCA is easily misdiagnosed or unrecognised and may be more frequent than is generally appreciated. ${ }^{12}$ It appears capable of causing a variety of ocular manifestations which can persist between attacks. Once recognised it is treatable, responding impressively to maintainence oral acetazolamide, $250 \mathrm{mg}$ twice daily. This diagnosis should be considered in patients presenting with intermittent ataxia or vertigo.
We thank Professor A E Harding for her advice and Elizabeth Chitty for her help in preparing the manuscript.

2 Farker TW Mustian VM. Vestibulocerebellar ataxia. Arch Neurol 1963; 8: 471-80.

3 Hill W, Sherman H. Acute intermittent familial cerebeller ataxia. Arch Neurol 1968; 18: 350-7.

4 White JC. Familial periodic nystagmus, vertigo and ataxia. Arch Neurol 1969; 20: 276-80.

5 Griggs RC, Moxley RT, Lafrance RA, McQuillen J. Hereditary paroxysmal ataxia: Response to acetazolamide. Neurology 1978; 28: 1259-64.

6 Donat JR, Auger R. Familial periodic ataxia. Arch Neurol 1979; 36: 568-9.

7 Aimard G, Vighetto A, Trillet M, Ventre JJ, Devic M. Ataxie paroxystique familiale sensible à l'acetazolamide. Rev Neurol (Paris) 1983; 139: 251-7.

8 Zasorin NL, Baloh RW, Myers LB. Acetazolamideresponsive episodic ataxia syndrome. Neurology 1983; 33: $1212-4$.

9 Livingstone IR, Gardner-Medwin D, Pennington RJT. Familial intermittent ataxia with possible $\mathrm{X}$-linked recessive inheritance. F Neurol Sci 1984; 64: 89-97.

10 Bouchard JP, Roberge C, van Gelder NM, Barbeau A. Familial periodic ataxia responsive to acetazolamide. $\operatorname{Can} \mathfrak{F}$ Neurol Sci 1984; 11: 550-3.

11 Trillet M, Gouttard M, Schott. Ataxie paroxystique familiale sensible à l'acetazolamide. Rev Neurol (Paris) 1985; 141: 203-6.

12 Gancher ST, Nutt JG. Autosomal dominant episodic ataxia: a heterogeneous syndrome. Movement Disorders 1986; 1: 249-

13 Friedman JH, Hollmann PA. Acetazolamide responsive hereditary paroxysmal ataxia. Movement Disorders 1987; 2: 67-82. 